\title{
Simultaneous use of sensory stimulation and motor exercise improves the manual skills of educable children with mental retardation at preprimary and primary school levels
}

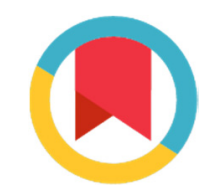

\author{
Raheleh Mollajani ${ }^{1,2}$, Seyed Saeid Taghavi ${ }^{1}$, Agha Fatemeh Hosseini ${ }^{1}$, Mona Farhadi ${ }^{1,3}$, Mana Jameie ${ }^{4,1}$, Melika Jameie ${ }^{4,1}$, \\ Seyed Behnamedin Jameie*5
}

Received: 2 Sep 2018

Published: 24 Dec 2019

\section{Abstract}

Background: Children with mental retardation have various clinical problems. They mostly have motor delay and sensory deficit. Neurorehabilitation focuses on restoring remaining abilities. Thus, the present study was designed to study the effects of simultaneous use of sensory-motor therapy on manual skills of children with mental retardation.

Methods: In this study, 120 educable boys and girls with mental retardation (9-12 years) were selected from 2 preprimary and primary exceptional centers in Tehran using stratified sampling method considering the geographical dispersion. The participants were divided into 2 equal trial and control groups using simple random sampling. Lincoln-Oseretsky Motor Development Scale, Purdue Pegboard test, and Handwriting Legibility Checklist of Persian Language were used. Simultaneous sensory stimulations and motor exercises were used for 3 one-hour weekly sessions for 12 consecutive weeks. Pre and posttests were done for evaluation. Using parametric paired and independent samples $t$ tests, the findings were analyzed in SPSS 23.

Results: The manual skills significantly improved following therapeutic use of simultaneous sensory stimulation and motor exercise $(\mathrm{p}=0.001)$. In the control group, the pre and post evaluation difference was not significant $(\mathrm{p}=0.813)$

Conclusion: Based on the findings of this study, simultaneous use of sensory-motor techniques can have better clinical results in the trial group compared to the control group. Thus, these types of techniques should be used more in clinics. However, further studies are needed for more comparison between separate applications of these techniques.

Keywords: Sensory stimulation, Motor exercises, Manual motor skills, Educable mentally Retarded children

Conflicts of Interest: None declared

Funding: None

\section{*This work has been published under CC BY-NC-SA 1.0 license. \\ Copyright $\odot$ Iran University of Medical Sciences}

Cite this article as: Mollajani R, Taghavi SS, Hosseini AF, Farhadi M, Jameie M, Jameie M, Jameie SB. Simultaneous use of sensory stimulation and motor exercise improves the manual skills of educable children with mental retardation at preprimary and primary school levels. Med $J$ Islam Repub Iran. 2019 (24 Dec);33:148. https://doi.org/10.47176/mjiri.33.148

\section{Introduction}

Manual skills are vital in interacting with the surrounding environment and allow human beings to understand

Corresponding author: Dr Seyed Behnamedin Jameie, jameie.sb@iums.ac.ir

1. Neuroscience Research Center, Iran University of Medical Sciences, Tehran, Iran

2. Institute for Cognitive Science Studies, Tehran, Iran

3. Department of Microbiology, Karaj Branch Islamic Azad University, Karaj, Iran

4. Faculty of Medicine, Shaheed Beheshti University of Medical Sciences, Tehran, Iran

5. Department of Medical Basic Sciences, Faculty of Allied Medicine, Iran University of Medical Sciences, Tehran, Iran the world and change it by hand (1). Using the hands for manipulation is the biological characteristic of human

\section{$\uparrow$ What is "already known" in this topic:}

Different sensory-motor-based therapeutic techniques such as Bobath, PNF, and Rood are used for children with mental retardation, which have shown various degrees of success. In the present paper, these techniques have been used with a different approach.

\section{$\rightarrow$ What this article adds:}

Children with mental retardation have motor delay and sensory deficits. Sensory stimulation and motor exercises are routinely used for patients and have their own clinical benefits. Although the effectiveness of simultaneous use of sensory stimulation and motor exercises are not compared with separate techniques, it seems that this style of using stimulation can have enough clinical benefits for patients without necessarily omitting separate methods in therapy. 
beings that dates back to more than 2.5 million years ago in a special species of humans caled Homo Habilis or Hand Man. Hand is a tool that is often used to do daily activities. Therefore, any degree of physical weakness and disability of the hands, particularly and other physical or mental disorders can affect the function of hands and deprive people of the full use of this vital tool $(1,2)$. The proper function of hands, particularly in delicate activities, depends on the interaction between the various regions of the brain, particularly, the sensory and motor cortex. Any disturbance in the normal growth of these regions of the brain, which is often seen in children with mental retardation, makes it difficult for the hands to follow normal patterns of action and impairs the activities of daily living (ADL) and rehabilitation and occupational activities (2, 3 ). Since these children lack the normal sensory-motor interactive basis for the development of cerebral cortex activity, the promotion of this manual skill is highly important. Therefore, considering the aforementioned points, this aspect of children's motor skills and the use of appropriate therapeutic approaches to improve them are of paramount importance. In the process of child development, sensory-motor processes play an important role in the skills required for the school age activities (3). Furthermore, since the preprimary and primary school educations are of particular importance in the development of higher levels of motor skills, this period is vital period in building and promoting manipulation skills and making significant changes in pencil holding skills (4-6). Therefore, it can help to assess the hand-related motor skills and the rate of improvement in this age (7). Recent studies have shown a significant relationship between sensory and motor components such as deep sense, tactile perception, the processing sensory-bodily ability, subtle motor skills of the hands, self-care performance, and social movement, and functioning $(8,9)$. Also, a relationship has been found between sensory-motor skills and handwriting quality. Therefore, it seems that sensory-motor skills and manipulation of the hands are important components of handwriting $(10,11)$. Studies have also shown that progress in manual skills and subtle movements of the hands is related to the increase in rational age in people with mental retardation, and children who show less accuracy in tactile areas, such as stereognosis, have a learning disability compared to their peers (12-14). In addition, studies have found evidence of progress in the development of subtle movements in preschool children attending occupational therapy sessions, which has been associated with the development of self-care skills in social function (7). Many studies have been conducted on the subtle movements and manual skills in occupational therapies due to importance of the issue. As no study has investigated the educable children with mental retardation, the present study was conducted to investigate the effect of simultaneous use of sensory stimulations and motor exercises on the manual skills of educable children with mental retardation at the preprimary and primary school levels. Preprimary and primary children were selected to participate in this study because younger children better react to therapy.

\section{Methods}

The present study was an interventional clinical trial in which, the effect of simultaneous use of sensory stimulations and specific motor exercises on the manual skills of children with mental retardation studying in 2 preprimary and primary levels for girls and boys were examined. The study population consisted of 120 educable boys and girls with mental retardation. They were selected by stratified sampling method considering the geographical dispersion of exceptional centers in Tehran and were divided into 2 groups of trial $(n=60)$ and control $(n=60)$ using simple random sampling. The type and severity of mental retardation and its level were confirmed by the contents of psychological, medical, and health records based on DSM-V criteria. The data collection tools in this study included a dynamometer (Jamar Hydraulic: Saman Preston Company) to measure hand power, the Lincoln-Oseretsky Motor Development Scale, and Purdue Pegboard test to evaluate fine movements. Also, Handwriting Legibility Checklist of the Persian Language was used to evaluate handwriting ability. To Measure bilateral grip strength, a calibrated Jamar hand-grip dynamometer was used (15). The Lincoln-Oseretsky Motor Development Scale evaluates motor functions of 6-14 year old children. It involves a wide variety of motor skills, including finger dexterity, eyehand coordination, and gross movements of hand arms, legs, and trunk with 36-items, which is used separately (16). The Purdue Pegboard test is a hand skill test that involves mounting pins, washers, and clutches and placing them in right holes. It is a test to evaluate manipulative skills designed to select employees in industrial jobs that require skill manipulation such as assembling, packaging, operating a special machine, and other manual routine tasks. The Purdo Pegboard test measures dexterity of the right hand, the left hand, and both hands separately. It also measures 2 types of activities: one involving hands, fingers, and arms gross movements; and tip of finger skills required for small assembly work (17).

The Handwriting Legibility Checklist of the Persian Language consists of 5 sentences of printing. It evaluates handwriting speed and legibility and exhibits excellent psychometric properties (18). Following the pretest evaluation, the therapeutic intervention was used for the trial group during 3 one-hour sessions per week for 12 continuous weeks by the same therapist. One-way blinded posttest evaluation was performed by another therapist. The therapeutic intervention used in this study was based on sensory integration approach, perceptual-motor development, and stability and strengthening activities for upper limbs presented elsewhere by other researchers (Tables 1 and 2) $(6,7,19)$.

The consent form was filled by parents, and in case of any disagreements of patients or their parents in any part of the study, therapy stopped. Enough attention was paid to the safety of all the techniques used in this study. Data were analyzed by paired and independent samples $t$ test using SPSS 21, and the results were presented in Mean \pm SD. $P$ value less than 0.05 was considered as significant. 


\begin{tabular}{ll}
\multicolumn{2}{l}{ Table 1 Sensory stimulations techniques } \\
\hline Row & Sensory Stimulations (30 min) \\
\hline 1 & All and single joint shaking \\
2 & Multivariate sensory stimulations \\
3 & Skin stretch in the muscular region \\
4 & Fast stretch of the upper limb joints in different directions of motor action \\
5 & Brushing on the large muscles of arm and forearm \\
6 & Brushing on the fingers \\
7 & Circular massage of the thenar and hypothenar area \\
8 & Pressing the tip of fingers \\
\hline & \\
Table 2. & Motor exercises techniques \\
\hline Row & Motor Exercises (active and resistive/30 min) \\
\hline 1 & Sand exercises \\
3 & Different weight bearing exercises on the hand \\
4 & Rolling exercises \\
5 & Rope exercises \\
6 & Gouache (painting) exercises \\
7 & Tire and rubber exercises \\
8 & Scissor exercises \\
9 & Matches and coins exercises \\
10 & Exercises with small objects \\
11 & Handwriting exercises \\
\hline
\end{tabular}

\section{Results}

The present study was conducted on 120 (60 girls and 60 boys) educable mentally retarded students at the preprimary and primary levels. The participants were categorized into 2 trial and control groups. The demographic information of the participants is presented in Figures 1, 2
$\& 3$. The results of this study showed a significant difference between the mean scores of pretest and posttest manual skills of the trial group according to the test results $(p<0.001)$ (Table 3$)$. In the control group, there was no significant difference in one-way motor speed, two-way motor speed, two-hands coordination, intermittent move-

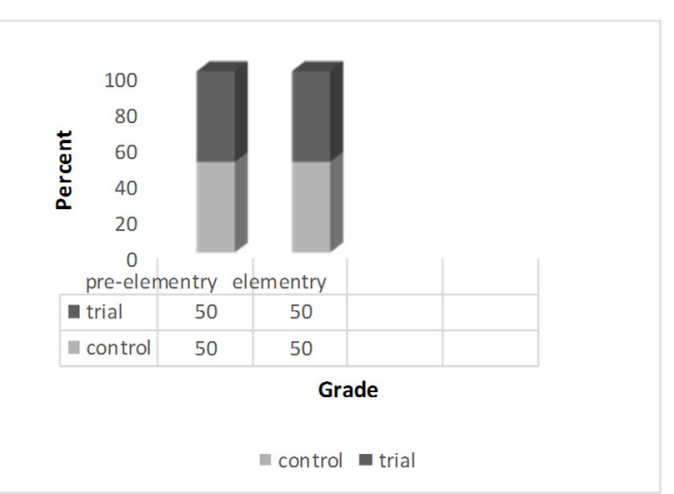

Fig. 1. Gender Data of the Subjects

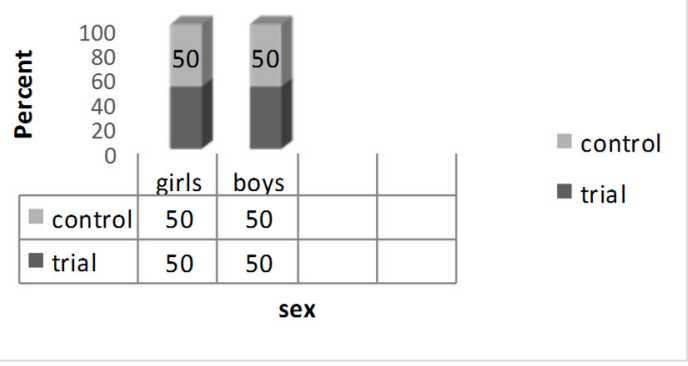

Fig. 2. Educational Grade Data of the Subject

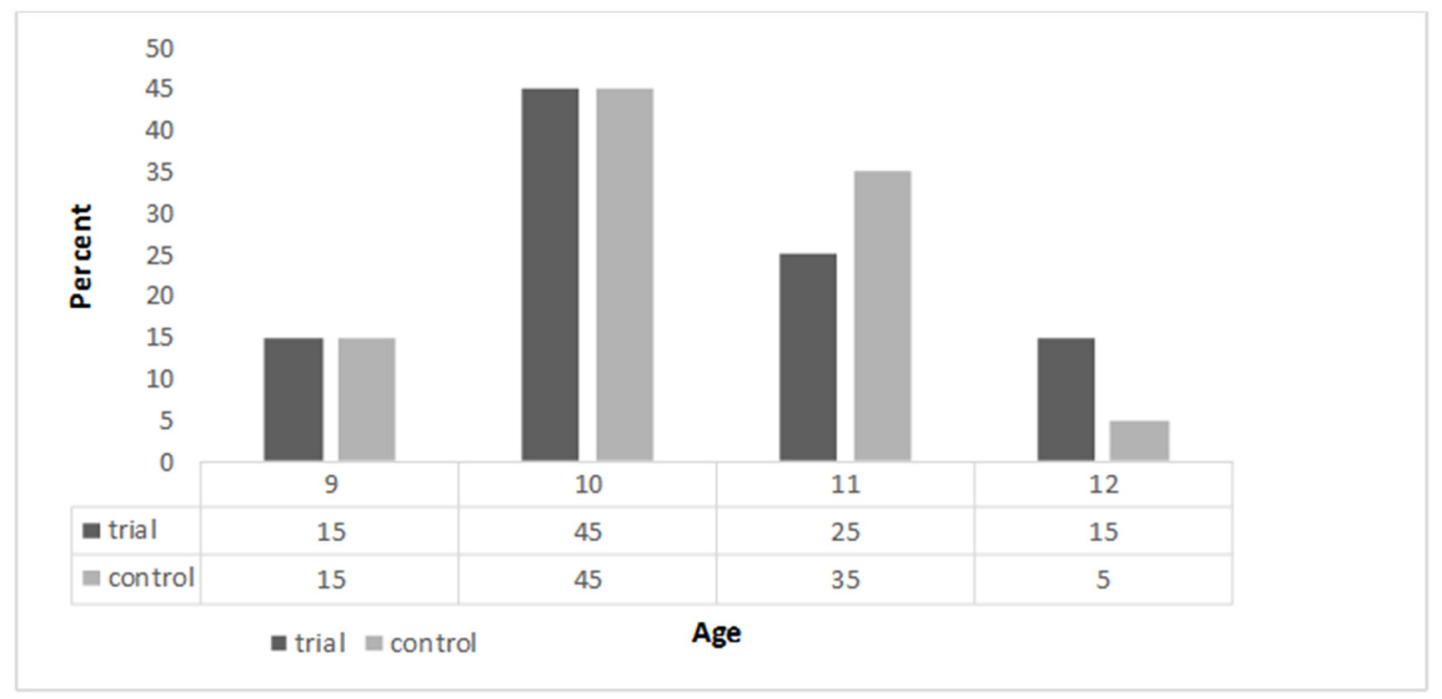

Fig. 3. Age Data of the Subjects 


\begin{tabular}{|c|c|c|c|c|c|}
\hline \multirow[t]{2}{*}{ Quantitative variables } & \multicolumn{2}{|c|}{ Pre-Test } & \multicolumn{2}{|c|}{ Post-Test } & \multirow[t]{2}{*}{$\mathrm{p}$} \\
\hline & Mean & SD & Mean & SD & \\
\hline One-way speed with left hand & 0.32 & 0.33 & 1.35 & 0.46 & $<0.001$ \\
\hline One-way speed with right hand & 0.26 & 0.26 & 1.35 & 0.46 & $<0.001$ \\
\hline Double-sided speed of the hands & 0.25 & 0.44 & 1.35 & 0.58 & $<0.001$ \\
\hline Two-hands coordination & 0.55 & 0.42 & 1.82 & 0.43 & $<0.001$ \\
\hline Movement precision of left hand & 0.51 & 0.36 & 2.21 & 2.23 & $<0.001$ \\
\hline Movement precision of right hand & 0.43 & 0.42 & 1.71 & 0.58 & $<0.001$ \\
\hline Intermittent movements with left hand & 0.57 & 0.46 & 2.32 & 0.52 & $<0.001$ \\
\hline Intermittent movements with right hand & 0.57 & 0.29 & 2.35 & 0.43 & $<0.001$ \\
\hline Eye and hand coordination with left hand & 0.56 & 0.39 & 2.19 & 1.22 & $<0.001$ \\
\hline Eye and hand coordination with right hand & 0.60 & 0.49 & 1.92 & 0.53 & $<0.001$ \\
\hline Motor planning & 0.10 & 0.30 & 2.5 & 1.10 & $<0.001$ \\
\hline Chinese Grain Test & 2.00 & 0.64 & 4.40 & 1.04 & $<0.001$ \\
\hline Purdo pegboard with left hand & 4.25 & 1.58 & 6.80 & 2.06 & $<0.001$ \\
\hline Purdo pegboard with right hand & 3.90 & 1.33 & 6.45 & 1.53 & $<0.001$ \\
\hline Two-hands Purdo pegboard & 0.80 & 0.76 & 2.75 & 0.91 & $<0.001$ \\
\hline Collection Purdo pegboard & 8.95 & 2.35 & 15.90 & 2.71 & $<0.001$ \\
\hline Assembly Purdo pegboard & 6.25 & 1.55 & 10.75 & 1.94 & $<0.001$ \\
\hline Power grip with left hand & 4.25 & 1.01 & 5.67 & 1.38 & $<0.001$ \\
\hline Power grip with right hand & 3.4 & 1.13 & 5.46 & 1.38 & $<0.001$ \\
\hline Thumb grip with left hand & 2.21 & 0.60 & 3.38 & 0.63 & $<0.001$ \\
\hline Thumb grip with right hand & 2.13 & 0.79 & 3.25 & 1.041 & $<0.001$ \\
\hline 3-finger dynamometer with left hand & 1.90 & 0.63 & 2.92 & 0.67 & $<0.001$ \\
\hline 3-finger dynamometer with right hand & 1.80 & 0.67 & 2.78 & 0.80 & $<0.001$ \\
\hline Handwriting & 4.25 & 1.74 & 7.15 & 1.72 & $<0.001$ \\
\hline
\end{tabular}

ments with left hand, and motor projection. However, the difference was considered significant in the strength, eye and hand coordination, intermittent movements with right hand, movement precision of the hands, and handwriting $(p<0.05)$ (Table 4). According to the results of independent $t$ test $(p<0.05)$, the mean difference between the pretest and posttest scores in manual skills was significant in the 2 groups (Table 5 ).

\section{Discussion}

The present study showed a significant difference between the pretest and posttest scores of fine manual skills in the trial group. The difference between the mean scores of manual skills in the pretest and posttest in the control group was not significant, except for the skills of holding strength, coordination of the eyes and hands, intermittent movements with the right hand, motor precision of the hands, and handwriting. This could be due to a series of

Table 4. Motor skills scores in control group

\begin{tabular}{|c|c|c|c|c|c|}
\hline \multirow[t]{2}{*}{ Quantitative variables } & \multicolumn{2}{|c|}{ Pre-Test } & \multicolumn{2}{|c|}{ Post-Test } & \multirow[t]{2}{*}{$\mathrm{p}$} \\
\hline & Mean & $\mathrm{SD}$ & Mean & $\mathrm{SD}$ & \\
\hline One-way speed with left hand & 0.16 & 0.20 & 0.16 & 0.20 & 0.712 \\
\hline One-way speed with right hand & 0.35 & 0.30 & 0.38 & 0.32 & 0.081 \\
\hline Double-sided speed of the hands & 0.20 & 0.41 & 0.25 & 0.44 & 0.223 \\
\hline Two-hands coordination & 0.55 & 0.39 & 0.60 & 0.38 & 0.161 \\
\hline Movement precision of left hand & 0.30 & 0.38 & 2.36 & 0.40 & 0.043 \\
\hline Movement precision of right hand & 0.46 & 0.43 & 0.56 & 0.43 & 0.029 \\
\hline Intermittent movements with left hand & 0.25 & 0.34 & 0.32 & 0.40 & 0.184 \\
\hline Intermittent movements with right hand & 0.42 & 0.43 & 2.52 & 0.44 & 0.041 \\
\hline Eye and hand coordination with left hand & 0.45 & 0.44 & 0.58 & 0.42 & $<0.001$ \\
\hline Eye and hand coordination with right hand & 0.63 & 0.44 & 0.85 & 0.41 & $<0.001$ \\
\hline Motor planning & 0.18 & 0.34 & 0.41 & 0.36 & 0.146 \\
\hline Chinese Grain Test & 2.10 & 0.64 & 2.20 & 0.60 & 0.083 \\
\hline Purdo pegboard with left hand & 4.05 & 1.46 & 4.20 & 1.43 & 0.081 \\
\hline Purdo pegboard with right hand & 4.05 & 1.46 & 4.20 & 1.43 & 0.083 \\
\hline Two-hands Purdo pegboard & 1.00 & 1.37 & 1.15 & 1.26 & 0.078 \\
\hline Collection Purdo pegboard & 8.40 & 2.96 & 9.00 & 3.04 & 0.091 \\
\hline Assembly Purdo pegboard & 5.25 & 2.22 & 5.40 & 2.06 & 0.264 \\
\hline Power grip with left hand & 3.92 & 1.49 & 4.00 & 1.45 & 0.031 \\
\hline Power grip with right hand & 4.53 & 1.50 & 4.58 & 1.47 & 0.049 \\
\hline Thumb grip with left hand & 2.28 & 0.54 & 3.45 & 5.10 & 0.032 \\
\hline Thumb grip with right hand & 2.57 & 0.61 & 2.62 & $0 / 62$ & 0.024 \\
\hline 3-finger dynamometer with left hand & 2.00 & 0.69 & 2.06 & 0.68 & 0.023 \\
\hline 3-finger dynamometer with right hand & 2.20 & 0.14 & 2.24 & 0.13 & 0.041 \\
\hline Handwriting & 3.70 & 0.43 & 3.95 & 1.79 & 0.022 \\
\hline
\end{tabular}

Table 5. Results for trial and control groups. As the table shows there is significant differences between two groups of study

\begin{tabular}{lccc}
\hline Groups & Mean (pre-post) & SD (pre-post) & $\mathrm{p}$ \\
\hline Trial & 69.70 & 8.12 & 0.001 \\
Control & 6.04 & 5.13 & 0.813 \\
\hline
\end{tabular}


uncontrollable intervening factors such as gameplay inside or outside the school, home activities, and ADL. These results are consistent with those of previous studies and theories $(6,7,9,10,19,20)$, which indicate that the aforementioned therapeutic programs are effective in improving manual skills. Thus, the results of this study showed that interventions, including simultaneous use of sensory stimulation and motor exercises, improve subtle motor function and handwriting skill in children with mental retardation.

Such results are consistent with the studies conducted on the effects of sensory integrity programs on the subtle motor skills. These findings have shown that improved sensory information processing results in improved motor stability and control in axial and proximal joints. This may be due to the fact that the process of gaining motor control and stability in upper extremities starts from the proximal to distal according to the growth theories $(8,20)$.

In the subtle motor disorders, 2 points should be considered: (1) the motor stability and control in the proximal parts of the shoulder belt and the axial joints of the body; (2) the motor stability and control in the distal joints of the limbs and the movement of the fingers. Subtle motor skills, including palmar hand motor skills, grasping, reaching the object, releasing, and moving individual fingers were controlled by at least 2 separate systems $(7,21$, 22 ). From the neuroanatomical point of view, the cortical and subcortical motor pathways affect the control of movement in more proximal regions and continue to distal parts. This proximal stability and control is a basis for control and stability in distal parts $(12,23)$. Studies have also revealed a significant relationship between sensorymotor components such as deep sense of touch, sensorybodily processing ability, and subtle hand movements, self-care performance, movement, and social functioning. In the process of child development, sensory-motor activity plays an important role in the skills required for school $(8,9,22)$. Studies that have examined subtle movements indicated a significant relationship between sensory-motor skills and subtle motor skills. They have also shown that improving the sensory-motor skills enhances subtle movements and handwriting $(7,10,24)$.

\section{Conclusion}

According to the findings of this study, sensory stimulation and motor exercises improve manual skills. In conclusion, using sensory stimulation and motor training exercises simultaneously can be more effective than each one alone. Although this finding has clinical applications and confirms the theory of motor-sensory loop, further investigations are needed to compare these data with the data achieved from groups that have received separated interventional techniques.

\section{Acknowledgments}

The authors would like to thank the Director of the Occupational Therapy Department of Iran University of Medical Sciences, the President of the Exceptional Education of Tehran Teaching and Training Authority, as well as authorities and teachers of the exceptional schools of Imam Ali and Ferdos for their cooperation and support.

Conflict of Interests

The authors declare that they have no competing interests.

\section{References}

1. Case-Smith J, O`brein JC. Occupational therapy for children. 6th ed; 2009; pp. 334-342

2. Bochner S. Ayres. Sensory integration and learning disorders: a question of theory and practice. Aust $\mathrm{J}$ Ment Retard. 1978;107(1):113-8

3. Fletcher JM. Classification and Identification of Learning Disabilities.4th ed; 2012; pp. 231-56.

4. Chien CW, Brown T, McDonald R. A framework of children's hand skills for assessment and intervention. Child Care Health Dev. 2009;68(6):194-207.

5. Markham LR. Influences of Handwriting Quality on Teacher Evaluation of Written Work. Am Educ Res J. 1976;13(1):124-31.

6. Case-Smith J. Effectiveness of School-Based Occupational Therapy Intervention on Handwriting. Am J Occup Ther. 2002;56(1):17-25.

7. Case-Smith J. Effects of Occupational Therapy Services on Fine Motor and Functional Performance in Preschool Children. Am J Occup Ther. 2000;54(4):372-80.

8. Tous-Ral JM, Muiños R, Liutsko L, Forero CG. Effects of Sensory Information, Movement Direction, and Hand Use on Fine Motor Precision. Percept Mot Skills. 2012;71(5):261-72.

9. Mulligan S, Wright J. An Examination of the Relationships Between Motor and Process Skills and Scores on the Sensory Profile. Am J Occup Ther. 2007;61(2):154-60.

10. Case-Smith J, Holland T, Lane A, White S. Effect of a coteaching handwriting program for first graders: One-group pretest-posttest design. Am J Occup Ther. 2012;66(4):396-405.

11. Volman MJM, Van Schendel BM, Jongmans MJ. Handwriting Difficulties in Primary School Children: A Search for Underlying Mechanisms. Am J Occup Ther. 2006;60(4):451-60.

12. Schenkman M, Bowman J, Gisbert R, Butler R. Clinical Neuroscience for Rehabilitation. 2012; 1st Edition. pp. 257-96.

13. Bowden JL, McNulty PA. Age-related changes in cutaneous sensation in the healthy human hand. Age. 2013;35:1077-1089.

14. Mawson AR. Toward a Theory of Childhood Learning Disorders, Hyperactivity, and Aggression. ISRN Psychiatry. 2012;76(3):1-19.

15. Bohannon RW. Hand-grip dynamometry provides a valid indication of upper extremity strength impairment in home care patients. J Hand Ther. 1998;11:258-260.

16. Sloan W. The Lincoln-Oseretsky Motor Development Scale. Genet Psychol Monogr.1955;51(2):183-252.

17. Tiffin J, Asher EJ. The Purdue Pegboard: norms and studies of reliability and validity. J Appl Psychol. 1948;32(3):234-247.

18. Schwellnus H, Carnahan H, Kushki A, Polatajko H, Missiuna C, Chau T. Effect of pencil grasp on the speed and legibility of handwriting in children. Am J Occup Ther. 2012;66(6):718-26.

19. Jones and Bartlett. Preparing for The Occupational Therapy Assistant National Board Exam: 45 Days and Counting. Second edition. 2016;11:521-539.

20. Rosen LD, Bailey ML, Becker D. Sensory Integration Therapies for Children With Developmental and Behavioral Disorders. Pediatrics. 2012;129(6):1186-9.

21. Shumway-Cook A, Woollacott MH. Motor Control Theory and Practical Applications. Second edition. 2000; pp. 295-314.

22. Szklut S, Cermak S. Neurological Rehabilitation; Learning disabilities. Third edition. 2014;9:312-344.

23. McCandless DW. Fundamental neuroscience. Metab Brain Dis. 1997; 12(1):85-93

24. Coppede AC, Matiko P, Okuda M, Capellini SA. Performance of children with learning difficulties in fine motor function and handwriting. J Hum Grotwth Dev. 2012;22(3):178-94. 